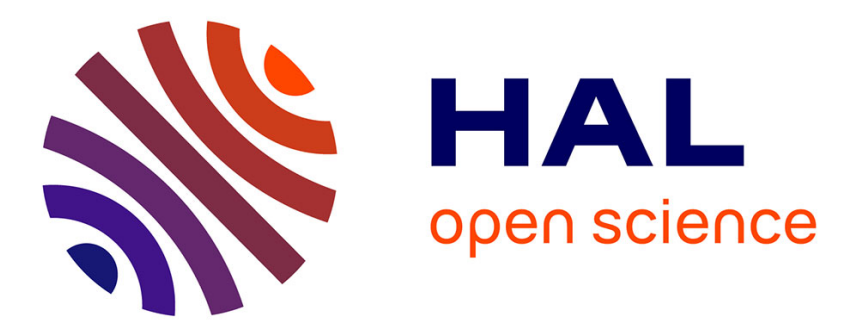

\title{
Enhanced Visible-Light Photocatalytic Performance of Electrospun rGO/TiO 2 Composite Nanofibers
}

Maryline Nasr, Sébastien Balme, Cynthia Eid, Roland Habchi, Philippe Miele, Mikhael Bechelany

\section{- To cite this version:}

Maryline Nasr, Sébastien Balme, Cynthia Eid, Roland Habchi, Philippe Miele, et al.. Enhanced Visible-Light Photocatalytic Performance of Electrospun rGO/TiO 2 Composite Nanofibers. Journal of Physical Chemistry C, 2016, 121 (1), pp.261 - 269. 10.1021/acs.jpcc.6b08840 . hal-01674790

\section{HAL Id: hal-01674790 \\ https://hal.umontpellier.fr/hal-01674790}

Submitted on 10 Jun 2021

HAL is a multi-disciplinary open access archive for the deposit and dissemination of scientific research documents, whether they are published or not. The documents may come from teaching and research institutions in France or abroad, or from public or private research centers.
L'archive ouverte pluridisciplinaire HAL, est destinée au dépôt et à la diffusion de documents scientifiques de niveau recherche, publiés ou non, émanant des établissements d'enseignement et de recherche français ou étrangers, des laboratoires publics ou privés. 


\title{
Enhanced Visible-Light Photocatalytic Performance of Electrospun $\mathrm{rGO} / \mathrm{TiO}_{2}$ Composite Nanofibers
}

\author{
Maryline Nasr, ${ }^{1,2}$ Sébastien Balme, ${ }^{1}$ Cynthia Eid, ${ }^{2}$ Roland Habchi, ${ }^{2}$ Philippe Miele, ${ }^{1}$ Mikhael \\ Bechelany*1
}

${ }^{1}$ Institut Européen des Membranes IEM, UMR-5635, Université de Montpellier, ENSCM, CNRS, Place Eugène Bataillon, F-34095 Montpellier Cedex 5, France

${ }^{2}$ EC2M, Faculty of Sciences 2, Research Platform for Nanosciences and Nanotechnologies, campus Pierre Gemayel, Fanar, Lebanese University, 90239 Lebanon

* Corresponding author : mikhael.bechelany@univ-montp2.fr, Phone: +33467149167, Fax: +33467149119

\section{ABSTRACT}

Reduced graphene oxide ( $\mathrm{rGO})$ / Titanium dioxide $\left(\mathrm{TiO}_{2}\right)$ composite nanofibers as photocatalytic materials were successfully elaborated by using electrospinning. The as-spun nanofibers with controlled ratio of $\mathrm{rGO}$ were annealed at $500^{\circ} \mathrm{C}$ under Nitrogen in a tubular furnace. Structural, morphological and optical characterizations demonstrate the success of rGO incorporation in the $\mathrm{TiO}_{2}$ nanofibers. The performances of these nanocomposites for photocatalytic application have been evaluated. The presence of rGO sheets decreases the band gap energy of $\mathrm{TiO}_{2} \mathrm{NFs}$ from $3.2 \mathrm{eV}$ to $2.9 \mathrm{eV}$. Hence, in the photodegradation of methyl orange (MO), a significant enhancement in the reaction rate was observed with $\mathrm{rGO} / \mathrm{TiO}_{2}\left(2\right.$ wt. \%) composite NFs compared to commercial $\mathrm{TiO}_{2}{ }^{-}$ P25. In addition, the kinetic of $\mathrm{MO}$ degradation by $\mathrm{rGO}$ TiO 2 (2wt. \%) composite NFs is 6 times higher than that by commercial $\mathrm{TiO}_{2}$. Thus, the photocatalytic activity of the composites $\mathrm{rGO} / \mathrm{TiO}_{2}$ significantly increases the visible light photo-response and improves the separation of photo-induced electron-hole pairs of $\mathrm{TiO}_{2}$. 


\section{INTRODUCTION}

Water is the most essential resource for the existence of all beings; nevertheless nowadays water poses a serious threat to all beings, from aquatic to human. Serious environmental pollution problem has aroused due to the increase of colored waste water induced by textile or dye industries. Different methods such as adsorption, membrane separation and chemical oxidation have been explored to remove dyes pollutants from water sources. In particular, photocatalysis can be considered as a "green" technology which can play an important role in solar energy conversion and degradation of organic pollutants ${ }^{1,2}$. Among various semiconductors, ${ }^{3}$ titanium dioxide $\left(\mathrm{TiO}_{2}\right)$ is considered as one of the most effective photocatalysts ${ }^{4}$ because of its strong photocatalytic performance, availability, long-term stability, nontoxicity, suitable redox potentials of conduction band and valence band, chemical inertness, stability against photocorrosion and low cost ${ }^{5,6}$. However, the fast electron-hole pair recombination of $\mathrm{TiO}_{2}$ significantly limits the efficiency of the photocatalytic reaction ${ }^{7}$. In addition, $\mathrm{TiO}_{2}$ has a wideband gap $(\mathrm{Eg}>3.20 \mathrm{eV})$ and it can only be excited by ultraviolet light (wavelength $<388 \mathrm{~nm})^{8}$. While the solar spectrum mostly consists of visible light $(44 \%)$, with a small proportion of UV radiation (7\%), the utilization of solar light as irradiation source for photocatalysis on $\mathrm{TiO}_{2}$ appears to be quite difficult. These limitations have been often overcome by doping $\mathrm{TiO}_{2}$ with other materials such as $\mathrm{Fe}^{9}, \mathrm{Pt}^{10}, \mathrm{~N}^{11}, \mathrm{SnO}_{2}{ }^{12}, \mathrm{Ag}^{13}$ and carbon nanotube ${ }^{14,15}$. This is one of the most effective methods for synthesizing visible light active $\mathrm{TiO}_{2}$ photocatalysts with high photocatalytic activities.

Recently, carbonaceous materials such as graphite, activated carbon, graphene and graphene oxide have attracted attention in order to increase the efficiency of $\mathrm{TiO}_{2}$ in catalytic application. Among the carbon family, graphene oxide has created a lot of attention due to the fact that it paves the way for solution based synthesis of graphene sheets. ${ }^{16-18}$ In addition GO has an excellent carrier mobility, and offers high transmittance, large surface area, chemical stability, easy processibility, as well as compatibility with various substrates. ${ }^{19-21}$ In addition, the band gap of graphene oxide can be tuned by varying the oxidation level from $2.7 \mathrm{eV}$ to $1.15 \mathrm{eV}^{22,23}$. These properties motivated us to synthesize rGO nanosheets $/ \mathrm{TiO}_{2}$ composite nanofibers using Electrospinning for reducing the titanium dioxide 
band gap and the recombination of photogenerated electron-hole pairs to enhance the photocatalytic activities under visible light. Electrospinning is a simple and cost-effective technique for the production of 1D nanostructure including polymer nanofibers, inorganic nanofibers and composite nanofibers. It permits the synthesis of nanofibers with diameter ranging from a few to several hundred of nanometers, depending on the polymer and processing conditions ${ }^{24}$. In the typical process of electrospinning, an electrical potential is applied between a syringe needle and a grounded target. When the electrostatic force exceeds the surface tension of the droplet formed at the tip of a syringe needle, charged fluid jet is ejected and finally nanofibers are deposited on a target plate ${ }^{25}$.

However, to our knowledge, there is no study concerning the preparation of $\mathrm{GO}$ nanosheets/ $\mathrm{TiO}_{2}$ composite nanofibers via the simple electrospinning technique. In the present work, GO was synthesized following the modified hummer's method ${ }^{26}$. The $\mathrm{GO} / \mathrm{TiO}_{2}$ composite nanofibers with different amounts of graphene oxide $(0,2,5,7$ wt. \% of mass Ti) have been elaborated for the first time by using electrospinning technique. The reduction of GO was performed by annealing the samples under nitrogen atmosphere without using any hazardous chemical. The $\mathrm{GO} / \mathrm{TiO}_{2}$ composite nanofibers were synthesized in order to red-shift the absorption edges of $\mathrm{TiO}_{2}$. The structural, morphological and optical properties of the prepared samples were analyzed. The performances of these materials for photocatalytic degradation of methyl orange (MO) under visible light have also been evaluated.

\section{MATERIALS AND METHODS}

\section{Materials}

Commercial graphite powder (99.95\%), titanium tetraisopropoxide (TTIP) $\operatorname{Ti}\left\{\mathrm{OCH}\left(\mathrm{CH}_{3}\right)_{2}\right\}_{4}(97 \%)$, polyvinylpyrrolidone $(\mathrm{PVP})(\mathrm{Mw}=13,00,000)$, acetic acid $(98 \%)$, phosphoric acid $\left(\mathrm{H}_{3} \mathrm{PO}_{4}, 85 \%\right)$, sulfuric acid $\left(\mathrm{H}_{2} \mathrm{SO}_{4}, 98 \%\right)$, hydrochloric acid $(\mathrm{HCl}, 30 \%)$, potassium permanganate $\left(\mathrm{KMnO}_{4}, 98 \%\right)$, hydrogen peroxide $\left(\mathrm{H}_{2} \mathrm{O}_{2}, 30 \%\right)$, methyl orange $(\mathrm{MO})$, and absolute ethanol were purchased from Sigma Aldrich, and used without any further purification. 


\section{Synthesis of Graphene Oxide}

Graphene oxide was synthesized from natural graphite powder, following modified Hummer's method ${ }^{27}$. Briefly, $3 \mathrm{~g}$ of graphite were dispersed in concentrated $\mathrm{H}_{2} \mathrm{SO}_{4}: \mathrm{H}_{3} \mathrm{PO}_{4}(9: 1,400 \mathrm{~mL})$ solution. $18 \mathrm{~g}$ of $\mathrm{KMnO}_{4}$ were added gradually to the mixture with stirring for $12 \mathrm{~h}$. Later on, the mixture was cooled down to room temperature and then $\mathrm{H}_{2} \mathrm{O}_{2}(3 \mathrm{~mL})$ was added. Brown precipitate was observed showing the exfoliation of graphene oxide from graphite. After one hour of stirring, GO was separated by centrifugation at $2697 \mathrm{G}$ for 10 minutes and the supernatant was decanted away. The resultant precipitates were washed several times with $30 \%$ hydrochloric acid and absolute ethanol. Finally, the obtained powder was dried at $50^{\circ} \mathrm{C}$ for 24 hours to obtain the pure graphene oxide.

\section{Preparation of $\mathrm{TiO}_{2}$ and rGO composite nanofibers}

The electrospinning process was used to prepare the rGO-incorporated $\mathrm{TiO}_{2}$ nanofibers. Spun solution was prepared in three steps. In the first one, different amounts of graphene oxide $(0,2,5,7$ wt. $\%$ of mass $\mathrm{Ti}$ ) and $2 \mathrm{ml}$ of absolute ethanol were sonicated for $12 \mathrm{~h}$ to disperse the graphene oxide into ethanol solution. In the second step, titanium tetraisopropoxide was dissolved in a mixture of $2 \mathrm{ml}$ of acetic acid and $3 \mathrm{ml}$ of ethanol mixed with $0.3 \mathrm{~g}$ of polyvinylpyrrolidone (PVP). The precursor mixture was stirred for $1 \mathrm{~h}$ at room temperature to obtain sufficient viscosity required for electrospinning. Finally, the GO solution was added to the precursor solution with vigorous magnetic stirring (150 rpm) for $30 \mathrm{~min}$. The homogeneous dark black solution was loaded into a plastic syringe having a stainless steel needle with a diameter of $0.7 \mathrm{~mm}$ at a constant flow rate of $1 \mathrm{ml} / \mathrm{h}$. The feeding rate was controlled by the syringe pump. The temperature level inside the electrospinning chamber was $38 \pm 5^{\circ} \mathrm{C}$. Nanofibers were collected on a rotating coil covered with an aluminum foil with a rotation speed of $400 \mathrm{rpm}$. The distance between the tip of the needle and the aluminum foil was maintained at $20 \mathrm{~cm}$, and a DC voltage of $25 \mathrm{kV}$ was applied. During electrospinning process, the applied electric field overcomes the surface tension of the polymeric solution, thereby ejecting a 
continuous jet, which upon subsequent solvent evaporation and bending produces nanofibers on the collector surface ${ }^{28}$. The electrospun $\mathrm{TiO}_{2}-\mathrm{GO}$ composite nanofibers were collected and then calcined at $500^{\circ} \mathrm{C}$ with a heating rate of $1^{\circ} \mathrm{C} \cdot \mathrm{min}^{-1}$ for $6 \mathrm{~h}$ in $\mathrm{N}_{2}$ environment in a tubular furnace in order to reduce the GO sheets ${ }^{17}$ to form $\mathrm{rGO} / \mathrm{TiO}_{2} \mathrm{NFs}$.

\section{Chemical and structural Characterization}

X-ray diffraction (XRD) measurements were carried out using a PANAlytical Xpert-PRO diffractometer equipped with an X'celerator detector using Ni-filtered $\mathrm{Cu}$-radiation $\left(\lambda=1.54{ }^{\circ} \mathrm{A}\right)$. Fourier-transform infrared (FTIR) spectra were recorded on a Nicolet 370 FTIR spectrometer using an ATR system. Transmission electron microscopy (TEM) images were taken with a PHILIPS-CM 20 (accelerating voltage: $200 \mathrm{KV}$ ). Scanning electron microscopy (SEM) images were taken with a Hitachi S4800, Japan (accelerating voltage: $1 \mathrm{KV}$ ). The UV-Vis absorbance spectra of methyl orange were recorded by a Jasco V-570 UV-VIS-NIR spectrophotometer. Raman spectra have been obtained from Horiba xplora, $\lambda=659 \mathrm{~nm}$. Energy-dispersive X-ray spectroscopy analysis (EDX) was taken with Zeiss EVO ED15 microscope coupled with an Oxford X-MaxN EDX detector.

\section{Photocatalytic activity measurement}

Methyl orange was used as a reference of organic pollutant to evaluate the photocatalytic activity of the $\mathrm{rGO} / \mathrm{TiO}_{2}$ composite NFs. The photocatalytic performance of the samples was evaluated by analyzing the decrease in concentration of the MO during exposure to visible light irradiation. The reaction temperature was kept constant at $25 \pm 0.2{ }^{\circ} \mathrm{C}$ by circulating water in a cylindrical tube surrounding the photo-reactor during the entire experiment. The decomposition was carried out in several beakers containing a suspension of $10 \mathrm{mg}$ of each sample in $25 \mathrm{~mL}$ of $\mathrm{MO}$ solution $(10 \mathrm{mg} / \mathrm{L})$ under visible light irradiation (obtained from a $150 \mathrm{~W}$ light source, emission wavelength $>400 \mathrm{~nm}$ ). The distance between the lamp and the dye solution was maintained at $10 \mathrm{~cm}$. First, the solution 
mixture was magnetically stirred for $30 \mathrm{~min}$ without irradiation to reach the adsorption-desorption equilibrium of $\mathrm{MO}^{14}$. Then the solution was irradiated with visible light for 2 hours. Each 30 minutes, $3 \mathrm{ml}$ of the sample solution was taken out and centrifuged to remove the catalyst. The centrifuged solutions were analyzed by a UV/Vis spectrometer. The absorbance spectra of MO (major absorption band around $462 \mathrm{~nm})^{29}$ were recorded to measure the change in the concentration of $\mathrm{MO}^{30}$. After irradiation, the photocatalytic degradation efficiency has been calculated by equation 1 :

Degradation efficiency $(\%)=\left(\mathrm{C}_{0}-\mathrm{C}\right) / \mathrm{C}_{0} \times 100$ (Equation 1)

where $\mathrm{C}_{0}$ and $\mathrm{C}$ are the initial concentration and the final concentration of dye before and after photoirradiation respectively. This equation shows the dye photocatalyst degradation percentage ${ }^{26}$.

\section{RESULTS AND DISCUSSION}

\section{Morphological, Structural and optical properties of $\mathrm{TiO}_{2} / \mathrm{rGO}$ nanofibers}

The $\mathrm{TiO}_{2}$ and $\mathrm{TiO}_{2} / \mathrm{GO}$ NFs with different amounts of graphene oxide were fabricated by electrospinning of a polymeric solution with titanium tetraisopropoxide as precursor. The morphological and microstructural details of $\mathrm{TiO}_{2}$ and $\mathrm{TiO}_{2} / \mathrm{GO}$ nanofibers were examined by SEM. Figure 1 displays the SEM images of the obtained $\mathrm{TiO}_{2}$ and GO-containing electrospun NFs after calcination at $500^{\circ} \mathrm{C}$ for $6 \mathrm{~h}$ under $\mathrm{N}_{2}$ atmosphere. The formation of highly interconnected networks of continuous, randomly oriented nanofibers can be clearly seen. It can also be observed that the incorporation of GO did not affect the nanofibrous morphology of $\mathrm{TiO}_{2}$.

The diameters have been obtained using the ImageJ, Java-based image processing software. The average diameter was measured on 100 randomly chosen nanofibers of each sample (Figure 1). After calcination, we measured an average diameter of $(141 \pm 5 \mathrm{~nm}),(263 \pm 7 \mathrm{~nm})$, $(293 \pm 10 \mathrm{~nm})$ and $(355 \pm 13 \mathrm{~nm})$ for samples with GO weight amount of $0,2,5$ and 7 wt. \% 
respectively. The average diameter of the nanofibers increases with the increase of the amount of graphene oxide. This can be attributed to the increase of the solution viscosity induced by inclusion of the GO in the electrospinning solution ${ }^{31}$. This increase reveals the successful incorporation of the graphene oxide in the $\mathrm{TiO}_{2}$ nanofibers. An energy dispersive X-ray spectrum (EDX) of $\mathrm{GO} / \mathrm{TiO}_{2} \mathrm{NFs}$ recorded along with elemental mapping is presented in Table 1. The EDX analysis revealed the molar ratio of $\mathrm{Ti}$ and $\mathrm{O}$ to be 1:2 for the above fibers, which is in good agreement with the stoichiometric ratio of $\mathrm{TiO}_{2}$. Comparing the $\mathrm{GO}$ doped fibers to the pure one, we can notice the increase of the carbon content in $\mathrm{GO}(2 \mathrm{wt} . \%) / \mathrm{TiO}_{2}$, $\mathrm{GO}(5 \mathrm{wt} . \%) / \mathrm{TiO}_{2}$ and $\mathrm{GO}(7 \mathrm{wt} . \%) / \mathrm{TiO}_{2}$.

Figure 2 illustrates the TEM images of $\mathrm{TiO}_{2} \mathrm{NFs}$ and $\mathrm{GO}\left(2\right.$ wt. \%) $/ \mathrm{TiO}_{2}$ composite NFs. Figure 2-a shows the granular aspect of the pure $\mathrm{TiO}_{2}$, with an approximate grain diameter of $10 \mathrm{~nm}$. When $\mathrm{TiO}_{2}$ is mixed with graphene oxide, the close up morphology of the fibers appears to be more linear with the absence of apparent grains and the presence of small voids. This could be due to the dispersion of $\mathrm{TiO}_{2}$ within the $\mathrm{GO}$ monosheets even though the flakes of GO do not appear in the image. We may suppose that the $\mathrm{TiO}_{2}$ is intercalated between the layers of GO with a certain spacing that may provide a better alignment inside the fiber as shown in figure 2-b. In addition, GO does not have any define structures because oxidation destroys the initial (002) peak of pristine graphite. Therefore the amorphous structure of GO (carbon based) could not be detected by selected area diffraction.

The crystalline phase of $\mathrm{TiO}_{2}, \mathrm{GO}\left(2\right.$ wt. \%) $/ \mathrm{TiO}_{2}, \mathrm{GO}(5 \mathrm{wt} . \%) / \mathrm{TiO}_{2}$, and $\mathrm{GO}(7 \mathrm{wt} . \%)$ $/ \mathrm{TiO}_{2}$ was analyzed by X-ray diffraction (XRD). The patterns in Figure 3 show the diffraction peaks of anatase phase of $\mathrm{TiO}_{2}$ (101), (200), (105), (211), (204) which correspond to $2 \theta=$ $25.5^{\circ}, 48.2^{\circ}, 54.1^{\circ}, 55.3^{\circ}$ and $64.2^{\circ}$ and three diffraction peaks of rutile phase of $\mathrm{TiO}_{2}(110)$, (101), (111) which correspond to $2 \theta=27.7^{\circ}, 35.8^{\circ}$ and $41.6^{\circ} 26,32$. The crystallite average sizes of $\mathrm{TiO}_{2}$ and $\mathrm{GO} / \mathrm{TiO}_{2}$ with different amounts of $\mathrm{GO}$ were estimated using the Scherrer 
equation $^{33}$. The calculated results show that the crystallite average sizes of $\mathrm{GO} / \mathrm{TiO}_{2}$ fibers increased as compared to pure $\mathrm{TiO}_{2}$ fibers. The crystallite sizes were found to be $9.4,18.4$, 15.5 and $10.1 \mathrm{~nm}$ for the samples $\mathrm{TiO}_{2}$, GO (2 wt. \%) $/ \mathrm{TiO}_{2}, \mathrm{GO}(5 \mathrm{wt} . \%) / \mathrm{TiO}_{2}$, and $\mathrm{GO}$ (7wt. \%) $/ \mathrm{TiO}_{2}$ respectively. However, when the amount of $\mathrm{GO}$ exceeds 5 wt. \% the crystallite size decreases which might be attributed to the agglomeration of GO sheets ${ }^{34}$. Evidence for stacks of graphene oxide sheets comes from the broad XRD peak of rGO (002) at around $2 \theta=$ $25^{\circ}$ which corresponds to the d-spacing interlayer distance between the sheets ${ }^{35}$. It is worth noting that the diffraction peak of (rGO) cannot be distinguished in the composite, probably due to the presence of the diffraction peak of $\mathrm{TiO}_{2}$ at the same position.

In order to confirm the crystalline quality and the formation of the $\mathrm{TiO}_{2}$ and $\mathrm{rGO} / \mathrm{TiO}_{2}$ nanofibers, the Raman spectrum was recorded in the range of $100-2000 \mathrm{~cm}^{-1}$. Figure 4 shows the Raman spectrum of $\mathrm{TiO}_{2}$, GO (2 wt. \%) $/ \mathrm{TiO}_{2}$, GO (5wt. \%) $/ \mathrm{TiO}_{2}$, and $\mathrm{GO}(7 \mathrm{wt} . \%)$ $/ \mathrm{TiO}_{2}$. For all samples we observe one peak corresponding to the active mode of anatase phase at $144 \mathrm{~cm}^{-1}\left(\mathrm{E}_{\mathrm{g}}\right)$ and three peaks corresponding to the active modes of rutile phase at $244 \mathrm{~cm}^{-1}\left(\mathrm{~B}_{1 \mathrm{~g}}\right), 447 \mathrm{~cm}^{-1}\left(\mathrm{E}_{\mathrm{g}}\right)$ and $612 \mathrm{~cm}^{-1}\left(\mathrm{~A}_{1 \mathrm{~g}}\right)^{36}$. More importantly, the Raman spectra of the composite $\mathrm{GO} / \mathrm{TiO}_{2}$ with different amounts of $\mathrm{GO}$ showed the broadened characteristic frequencies at $1365 \mathrm{~cm}^{-1}$ and $1612 \mathrm{~cm}^{-1}$, which correspond to the $\mathrm{D}$ and $\mathrm{G}$ band, respectively ${ }^{37}$. These two bands confirm that the GO was successfully introduced into the nanofibers during electrospinning. The detected carbon comes essentially from the addition of GO and not from the initial polymer, as particularly verified by the Raman spectroscopy. In fact, the carbon in graphene oxide sheets is distributed over a honeycomb structure which exhibits a $\mathrm{sp}^{2}$-hybridized carbon system resulting into the $\mathrm{D}$ and $\mathrm{G}$ vibration modes. The $\mathrm{G}$ band $\left(1612 \mathrm{~cm}^{-1}\right)$ is due to the stretching of the $\mathrm{C}-\mathrm{C}$ bond whilst the $\mathrm{D}$ band $\left(1360 \mathrm{~cm}^{-1}\right)$ is an in-plane vibrational mode, as clearly shown in the GO (2 wt. \%) $/ \mathrm{TiO}_{2}$ sample. When the percentage of GO is increased (5 wt \% and 7 wt \%), the interaction between the stacked layers 
will change the spectrum namely by widening the D band and creating a small red shift as shown in Figure 4B. These particularities are obviously not present in the pure $\mathrm{TiO}_{2} \mathrm{sample}^{38}$. The ratio between the intensity of $\mathrm{D}$ and $\mathrm{G}$ bands has been used as a parameter to evaluate the reduction of GO. Changes in the relative intensities of the $\mathrm{D}$ and $\mathrm{G}$ bands (D/G) indicate the modifications of the electronic conjugation state of the GO during reduction after $\mathrm{N}_{2}$ calcination $^{39}$. The $\mathrm{D} / \mathrm{G}$ ratio can be influenced by edges, charge puddles, ripples and many other defects ${ }^{40}$. After calculation of the $\mathrm{D} / \mathrm{G}$ ration for different GO amounts, it was found to be $1.1,1.24$, and 1.36 for $\mathrm{GO}(2$ wt. $\%) / \mathrm{TiO}_{2}$, GO (5wt. \%) $/ \mathrm{TiO}_{2}$, and $\mathrm{GO}(7 \mathrm{wt} . \%) / \mathrm{TiO}_{2}$, respectively. Since the Raman D/G intensity ratio is inversely proportional to the average size of the $\mathrm{sp}^{2}$ domains, the increase of the $\mathrm{D} / \mathrm{G}$ intensity ratio suggests that smaller in-plane $\mathrm{sp}^{2}$ domains are formed during the reduction of GO after $\mathrm{N}_{2}$ annealing ${ }^{41}$, which means that the $\mathrm{GO}\left(2\right.$ wt. \%) $/ \mathrm{TiO}_{2}$ was more reduced than $\mathrm{GO}(5 \mathrm{wt} . \%) / \mathrm{TiO}_{2}$, and $\mathrm{GO}(7 \mathrm{wt} . \%) / \mathrm{TiO}_{2}$. This might be related to the time of the heat treatment. A larger amount of GO required a longer time of calcination for the removal of the oxygen-containing functional groups ${ }^{23}$.

The various functional groups present in the $\mathrm{TiO}_{2}, \mathrm{GO}$ and $\mathrm{rGO} / \mathrm{TiO}_{2}$ nanofibers were confirmed by using Fourier transform infrared (FTIR) spectroscopy as shown in Figure 5. Based on previous studies, the FTIR spectrum of GO illustrates the presence of $\mathrm{C}=\mathrm{O}(1728$ $\mathrm{cm}^{-1}$ ) from stretching vibrations from carbonyl and carboxylic groups, C-OH $\left(1222 \mathrm{~cm}^{-1}\right)$ from stretching vibrations, C-O $\left(1035 \mathrm{~cm}^{-1}\right)$, and C-O $\left(968 \mathrm{~cm}^{-1}\right)$ from carbonyl, carboxylic and epoxy groups, which confirms the presence of oxygen-containing functional groups. The peak at $1600 \mathrm{~cm}^{-1}$ arises due to the $\mathrm{C}-\mathrm{C}$ vibrations from the graphitic domains. The broad peak at $3423 \mathrm{~cm}^{-1}$ is due to the adsorbed water content in the surface of $\mathrm{GO}^{42}$. These functional groups present in the GO renders it hydrophilic while the graphite and graphene are hydrophobic ${ }^{34}$. In the case of the annealed $\mathrm{TiO}_{2}$ and $\mathrm{TiO}_{2} / \mathrm{GO}$ (Figure 5a-d), the characteristic absorption band of $\mathrm{TiO}_{2}$ at $800-1200 \mathrm{~cm}^{-1}$ is attributed to $\mathrm{Ti}-\mathrm{O}$ bond. The bands related to 
the carbon-containing functional groups $\mathrm{C}=\mathrm{C}$ (indexed in the Figure 5) are observed, and increase with the GO amounts. The peak at $1730 \mathrm{~cm}^{-1}$ almost disappears because of the removal of $\mathrm{C}=\mathrm{O}$. This proves that many oxygen groups were removed and confirms the transformation from $\mathrm{GO} / \mathrm{TiO}_{2}$ to $\mathrm{rGO} / \mathrm{TiO}_{2}$ during the $\mathrm{N}_{2}$ calcination ${ }^{38}$.

The UV-Vis absorption spectroscopy measurement of pure $\mathrm{TiO}_{2}$ NFs and $\mathrm{rGO} / \mathrm{TiO}_{2}$ composite nanofibers was carried out to investigate the optical properties of the samples and the results are shown in Figure 6. The UV-Vis absorption spectra of the GO (2 wt. \%) / $\mathrm{TiO}_{2}$, $\mathrm{GO}(5 \mathrm{wt} . \%) / \mathrm{TiO}_{2}$ and $\mathrm{GO}(7 \mathrm{wt} . \%) / \mathrm{TiO}_{2}$ nanocomposite indicates that it absorbs light at 420, 406 and $391 \mathrm{~nm}$ (indexed in the Figure 6) corresponding to a band gap of 2.95, 3.1 and $3.17 \mathrm{eV}$, respectively. Compared to the $\mathrm{TiO}_{2}$ nanofibers (absorption edge: $386 \mathrm{~nm}$, band gap energy: $3.2 \mathrm{eV}$ ), the absorption edges of $\mathrm{rGO} / \mathrm{TiO}_{2}$ composite nanofibers are red-shifted ${ }^{43}$. Actually, the GO (2 wt. \%) has the lowest band gap since it is the most reduced sample as already confirmed by Raman analyses, and is expected to exhibit enhanced photocatalytic activity compared to other samples. The photoactivity is measured and evaluated in the next section. Thus, we can say that the incorporation of GO sheets into $\mathrm{TiO}_{2} \mathrm{NFs}$ creates energetic levels which decrease the band gap energy of $\mathrm{TiO}_{2}$ and increase the visible light catalytic activity of $\mathrm{TiO}_{2}$ nanofibers.

\section{Photocatalytic degradation of methyl orange by $\mathrm{TiO}_{2} / \mathrm{rGO}$ nanofibers}

The photocatalytic activities of $\mathrm{TiO}_{2} / \mathrm{rGO}$ NFs with different GO amounts were evaluated by degradation of methyl orange (MO) under visible light (wavelength $>400 \mathrm{~nm}$ ). MO was selected as a model organic pollutant. Figure 7a-f shows the UV-Vis absorbance spectra of MO solution (major absorption band around $462 \mathrm{~nm}$ ) with different time intervals $0,30,60$, 90 and 120 min after 60 min storage in dark for excluding the interference of adsorption. For 
comparison, the photocatalytic activities of $\mathrm{TiO}_{2} \mathrm{NFs}$ and commercial $\mathrm{TiO}_{2}-\mathrm{P} 25$ were also tested under identical experimental conditions. The results indicate that MO is stable and difficult to be photodegraded in the absence of photocatalyst. After irradiation $120 \mathrm{~min}$, MO was degraded up to $40 \%$ in the presence of $\mathrm{TiO}_{2}$ nanofibers, compared to $35 \%$ degradation by commercial granular $\mathrm{TiO}_{2}-\mathrm{P} 25$ (Figure 8). Therefore, in case of pure $\mathrm{TiO}_{2}$, it is well known that $\mathrm{TiO}_{2}$ NFs have a larger active surface area compared to the commercial $\mathrm{TiO}_{2}-\mathrm{P} 25$ nanoparticles ${ }^{44}$.

Most significant, the GO (2 wt. \%) $/ \mathrm{TiO}_{2}$ and $\mathrm{GO}(5$ wt. $\%) / \mathrm{TiO}_{2} \mathrm{NFs}$ show remarkably enhanced photocatalytic activities, the MO degradation being $90 \%$ and $63 \%$ respectively. The GO (2 wt. \%) $/ \mathrm{TiO}_{2} \mathrm{NFs}$ exhibits the higher photocatalytic activity. With higher GO amount 7 wt. $\%$, the activity of $\mathrm{TiO}_{2} / \mathrm{rGO} \mathrm{NFs}$ is gradually decreased; the MO degradation was just 26\%. For the composites GO (2 wt. \%) $/ \mathrm{TiO}_{2}$ and $\mathrm{GO}\left(5\right.$ wt. \%) $/ \mathrm{TiO}_{2}$, the absorption edges are red shifted and the band gap energy decreases with the rGO incorporation. In addition, the photo electrons were quickly transferred to the rGO layers, which reduce the probability of the electron-hole recombination in $\mathrm{TiO}_{2}$. Thus, more photo electrons were available compared to pure $\mathrm{TiO}_{2} \mathrm{NFs}$, to take part in the photodegradation process. However, the use of an excessive amount of $\mathrm{GO}$ in the $\mathrm{GO}(7 \mathrm{wt} . \%) / \mathrm{TiO}_{2}$ composite reduced the light absorption on the $\mathrm{TiO}_{2}$ surface. This leads to a decrease of photoexcited electrons ${ }^{45}$. This excess of GO (7wt. \%) also increased the opportunity for the recombination of the photo-generated electron-hole pairs, by increasing the collision among the photogenerated electrons and holes $^{46}$. It was well known that the photocatalytic activity is mainly governed by crystalline phase, light absorption capacity and separation efficiency of electron-hole pairs ${ }^{47}$. From the $\mathrm{XRD}$ analysis, the crystallite average sizes of $\mathrm{TiO}_{2}$ increased after introducing $\mathrm{GO}$ sheets for GO (2 wt. \%) $/ \mathrm{TiO}_{2}$ NFs. Therefore, the relevant explanation for the high phototocatalytic activity of GO (2 wt. \%) $/ \mathrm{TiO}_{2} \mathrm{NFs}$ should be ascribed to the differences in the GO reduction. 
As confirmed by Raman analyses and UV-Vis absorption presented above, more GO in GO (2 wt. \%) $/ \mathrm{TiO}_{2} \mathrm{NFs}$ was reduced than that in $\mathrm{GO}\left(5\right.$ wt. \%) $/ \mathrm{TiO}_{2}$ and $\mathrm{GO}(7$ wt. $\%) / \mathrm{TiO}_{2} \mathrm{NFs}$ which means the lowest band-gap energy $(2.9 \mathrm{eV})$. These results indicate that GO (2 wt. \%) $/ \mathrm{TiO}_{2}$ composite NFs has excellent absorption capacity of visible light and lower recombination rate of electron-hole pair.

Figure 9 shows the different kinetic linear curves. The photodegradation reactions follow a Langmuir-Hinshelwood first-order kinetics model ${ }^{48}$. The explanation is described as follows:

$$
\mathrm{r}=\frac{d C}{d t}=\frac{k K C}{(1+K C)}
$$

where $\mathrm{r}$ is the degradation rate of $\mathrm{MO}\left(\mathrm{mg}(\mathrm{L} \mathrm{min})^{-1}\right), \mathrm{C}$ is the concentration of a $\mathrm{MO}$ solution $\left(\mathrm{mg} \mathrm{L}^{-1}\right), \mathrm{t}$ is the irradiation time, $\mathrm{k}$ is the reaction rate constant $\left(\mathrm{mg}(\mathrm{L} \mathrm{min})^{-1}\right)$, and $\mathrm{K}$ is the adsorption coefficient of $\mathrm{MO}\left(\mathrm{mg} \mathrm{L}^{-1}\right)$. Since the initial concentrations $\left(\mathrm{C}_{0}=10 \mathrm{mg} \mathrm{L}^{-1}\right)$ of the MO solutions are very low in the present experiments, this equation can be simplified to an apparent first-order model ${ }^{48}$ :

$$
\ln \left(\mathrm{C}_{0} / \mathrm{C}\right)=\mathrm{kKt}=\mathrm{k}_{\mathrm{a}} \mathrm{t} \quad \text { (Equation 3) }
$$

where $\mathrm{k}_{\mathrm{a}}$ is the apparent first-order rate constant $\left(\mathrm{min}^{-1}\right)$ and $\mathrm{C}$ is the concentration at time $\mathrm{t}$. $\mathrm{k}_{\mathrm{a}}$ obtained from the linear dependence between $\ln \left(\mathrm{C}_{0} / \mathrm{C}\right)$ and time (Figure 9$)$ are reported in Table 2. The increasing order of the rate constants in the samples is: $\mathrm{GO}(2 \mathrm{wt} . \%) / \mathrm{TiO}_{2}<$ GO (5wt. \%) $/ \mathrm{TiO}_{2}<\mathrm{TiO}_{2} \mathrm{NFs}<\mathrm{TiO}_{2}-\mathrm{P} 25<\mathrm{GO}(7 \mathrm{wt} . \%) / \mathrm{TiO}_{2}<\mathrm{MO}$. The rate constant exhibits a maximum of $0.0186 \mathrm{~min}^{-1}$ for $\mathrm{GO}(2 \mathrm{wt} . \%) / \mathrm{TiO}_{2}$ nanocomposites, which is around 6 times higher than that of commercial $\mathrm{TiO}_{2}-\mathrm{P} 25$ and $\mathrm{TiO}_{2}$ NFS. Thus, for the more reduced sample GO (2 wt. \%) $/ \mathrm{TiO}_{2} \mathrm{NFs}$ as confirmed above, visible-light photocatalytic activity is significantly improved. 
In the present work, the fact of using the simple electrospinning technique to synthesize composite nanofibers of $\mathrm{rGO} / \mathrm{TiO}_{2}$ for photocatalytic application is novel. The degradation efficiency $(90 \%)$ obtained by using the $\mathrm{rGO} / \mathrm{TiO}_{2}$ composite nanofibers in our case is greater in comparison to what has been reported before ${ }^{37,43}$. The enhancement is induced by the special morphology of the nanofibers that presents improved active surface area in comparison to $\mathrm{rGO} / \mathrm{TiO}_{2}$ nanoparticles ${ }^{44}$.

\section{CONCLUSION}

In summary, $\mathrm{rGO} / \mathrm{TiO}_{2}$ composite nanofibers with different $\mathrm{GO}$ amounts were successfully prepared by electrospinning. All the samples were annealed at $500^{\circ} \mathrm{C}$ in $\mathrm{N}_{2}$ atmosphere for 6 hours. The SEM images showed an increase in the average diameter with the increase of rGO amount and confirmed that the one dimensional morphology was maintained. The correlation between the domain size of the $\mathrm{TiO}_{2}$ crystalline structure and the $\mathrm{GO}$ incorporation effect was clearly observed in the TEM and XRD results. Raman and FTIR confirmed the reduction of GO after calcinations in $\mathrm{N}_{2}$ atmosphere. The decreasing of $\mathrm{TiO}_{2} \mathrm{NFs}$ band gap energy from $3.2 \mathrm{eV}$ to $2.9 \mathrm{eV}$ due to the presence of rGO sheets was confirmed by UV-Vis analysis. The incorporation of rGO significantly increases the visible light photo-response and improves the separation of the photo-induced electron-hole pairs of $\mathrm{TiO}_{2}$. Remarkably, the optimal percentage of introducing and reducing $\mathrm{GO}$ is $2 \mathrm{wt} . \% / \mathrm{TiO}_{2}$. Under this condition, the photocatalytic degradation of methyl orange under visible light is 6 times higher than that of commercial $\mathrm{TiO}_{2}-\mathrm{P} 25$. In addition after $120 \mathrm{~min} 90 \%$ of $\mathrm{MO}$ is degraded against $35 \%$ degradation by commercial $\mathrm{TiO}_{2}$. Thus, incorporating rGO into $\mathrm{TiO}_{2} \mathrm{NFs}$ is an efficient and simple way for enhancing the visible-light photocatalytic activity. As a result, we have successfully prepared $\mathrm{rGO} / \mathrm{TiO}_{2}$ composite nanofibers that could be used as catalysts in the 
degradation of different organic molecules under visible light, as well as electrolyte membrane for fuel cell application and many other membrane applications ${ }^{49}$.

ACKNOWLEDGEMENTS: M. Nasr would like to thank the Lebanese University for the

PhD funding. This study was partially supported by the ANR project ANR-14-CE07-0011 "BONALD". The authors wish also to thank Fabienne WARMONT from Université d'Orléans for TEM analysis.

\section{REFERENCES}

(1) Sofianou, M.-V.; Tassi, M.; Psycharis, V.; Boukos, N.; Thanos, S.; Vaimakis, T.; Yu, J.; Trapalis, C., Solvothermal Synthesis and Photocatalytic Performance of Mn 4+-Doped Anatase Nanoplates with Exposed \{001\} Facets. Appl. Catal., B 2015, 162, 27-33.

(2) Chen, C.; Ma, W.; Zhao, J., Semiconductor-Mediated Photodegradation of Pollutants under Visible-Light Irradiation. Chem. Soc. Rev. 2010, 39, 4206-4219.

(3) Nasr, M.; Viter, R.; Eid, C.; Warmont, F.; Habchi, R.; Miele, P.; Bechelany, M., Synthesis of Novel ZnO/ZnAl2O4 Multi Co-Centric Nanotubes and Their Long-Term Stability in Photocatalytic Application. RSC Adv. 2016, 6, 103692 - 103699.

(4) Asahi, R.; Morikawa, T.; Ohwaki, T.; Aoki, K.; Taga, Y., Visible-Light Photocatalysis in Nitrogen-Doped Titanium Oxides. Science 2001, 293, 269-271.

(5) Kim, C. H.; Kim, B.-H.; Yang, K. S., TiO2 Nanoparticles Loaded on Graphene/Carbon Composite Nanofibers by Electrospinning for Increased Photocatalysis. Carbon 2012, 50, 2472-2481.

(6) Thirugnanam, L.; Kaveri, S.; Dutta, M.; Jaya, N. V.; Fukata, N., Porous Tubular Rutile TiO2 Nanofibers: Synthesis, Characterization and Photocatalytic Properties. J. Nanosci. Nanotechnol. 2014, 14, 3034-3040.

(7) Spasiano, D.; Rodriguez, L. d. P. P.; Olleros, J. C.; Malato, S.; Marotta, R.; Andreozzi, R., TiO2/Cu (Ii) Photocatalytic Production of Benzaldehyde from Benzyl Alcohol in Solar Pilot Plant Reactor. Appl. Catal., B 2013, 136, 56-63.

(8) Wang, J.; Wang, P.; Cao, Y.; Chen, J.; Li, W.; Shao, Y.; Zheng, Y.; Li, D., A High Efficient Photocatalyst Ag3VO4/TiO2/Graphene Nanocomposite with Wide Spectral Response. Appl. Catal., B 2013, 136, 94-102.

(9) Kim, D. H.; Hong, H. S.; Kim, S. J.; Song, J. S.; Lee, K. S., Photocatalytic Behaviors and Structural Characterization of Nanocrystalline Fe-Doped TiO2 Synthesized by Mechanical Alloying. J. Alloys Compd. 2004, 375, 259-264.

(10) Formo, E.; Lee, E.; Campbell, D.; Xia, Y., Functionalization of Electrospun TiO2 Nanofibers with Pt Nanoparticles and Nanowires for Catalytic Applications. Nano Lett. 2008, $8,668-672$. 
(11) Zhang, L.; Li, X.; Chang, Z.; Li, D., Preparation, Characterization and Photoactivity of Hollow N, Co Co-Doped TiO2/SiO2 Microspheres. Mater. Sci. Semicond. Process. 2011, 14, 52-57.

(12) Xu, X.; Yang, G.; Liang, J.; Ding, S.; Tang, C.; Yang, H.; Yan, W.; Yang, G.; Yu, D., Fabrication of One-Dimensional Heterostructured $\mathrm{TiO} 2$ @ $\mathrm{SnO} 2$ with Enhanced Photocatalytic Activity. J. Mater. Chem. A 2014, 2, 116-122.

(13) He, L.; Dumée, L. F.; Liu, D.; Velleman, L.; She, F.; Banos, C.; Davies, J. B.; Kong, L., Silver Nanoparticles Prepared by Gamma Irradiation across Metal-Organic Framework Templates. RSC Adv. 2015, 5, 10707-10715.

(14) Jiang, L.; Huang, Y.; Liu, T., Enhanced Visible-Light Photocatalytic Performance of Electrospun Carbon-Doped TiO2/Halloysite Nanotube Hybrid Nanofibers. J. Colloid Interface Sci. 2015, 439, 62-68.

(15) Dumée, L.; Hill, M. R.; Duke, M.; Velleman, L.; Sears, K.; Schütz, J.; Finn, N.; Gray, S., Activation of Gold Decorated Carbon Nanotube Hybrids for Targeted Gas Adsorption and Enhanced Catalytic Oxidation. J. Mater. Chem. 2012, 22, 9374-9378.

(16) Nainani, R. K.; Thakur, P., Facile Synthesis of TiO2-RGO Composite with Enhanced Performance for the Photocatalytic Mineralization of Organic Pollutants. Water Sci. Technol. 2016, 73, 1927-1936.

(17) Lavanya, T.; Satheesh, K.; Dutta, M.; Jaya, N. V.; Fukata, N., Superior Photocatalytic Performance of Reduced Graphene Oxide Wrapped Electrospun Anatase Mesoporous TiO2 Nanofibers. J. Alloys Compd. 2014, 615, 643-650.

(18) Fan, W.; Lai, Q.; Zhang, Q.; Wang, Y., Nanocomposites of TiO2 and Reduced Graphene Oxide as Efficient Photocatalysts for Hydrogen Evolution. J. Phys. Chem. C 2011, $115,10694-10701$.

(19) Cong, Y.; Long, M.; Cui, Z.; Li, X.; Dong, Z.; Yuan, G.; Zhang, J., Anchoring a Uniform TiO2 Layer on Graphene Oxide Sheets as an Efficient Visible Light Photocatalyst. Appl. Surf. Sci. 2013, 282, 400-407.

(20) Pan, X.; Zhao, Y.; Liu, S.; Korzeniewski, C. L.; Wang, S.; Fan, Z., Comparing Graphene-TiO2 Nanowire and Graphene-TiO2 Nanoparticle Composite Photocatalysts. ACS Appl. Mater. Interfaces 2012, 4, 3944-3950.

(21) Dutta, M.; Sarkar, S.; Ghosh, T.; Basak, D., ZnO/Graphene Quantum Dot Solid-State Solar Cell. J. Phys. Chem. C 2012, 116, 20127-20131.

(22) Bai, X.; Zhang, X.; Hua, Z.; Ma, W.; Dai, Z.; Huang, X.; Gu, H., Uniformly Distributed Anatase TiO2 Nanoparticles on Graphene: Synthesis, Characterization, and Photocatalytic Application. J. Alloys Compd. 2014, 599, 10-18.

(23) Velasco-Soto, M.; Pérez-García, S.; Alvarez-Quintana, J.; Cao, Y.; Nyborg, L.; LiceaJiménez, L., Selective Band Gap Manipulation of Graphene Oxide by Its Reduction with Mild Reagents. Carbon 2015, 93, 967-973.

(24) Doshi, J.; Reneker, D. H. In Electrospinning Process and Applications of Electrospun Fibers, Ind. Appl. Soc. Annu. Meet, 1993., Conf. Rec. IEEE, 1698-1703.

(25) MacDiarmid, A.; Jones, W.; Norris, I.; Gao, J.; Johnson, A.; Pinto, N.; Hone, J.; Han, B.; Ko, F.; Okuzaki, H., Electrostatically-Generated Nanofibers of Electronic Polymers. Synt. Met. 2001, 119, 27-30.

(26) Kaveri, S.; Thirugnanam, L.; Dutta, M.; Ramasamy, J.; Fukata, N., Thiourea Assisted One-Pot Easy Synthesis of Cds/RGO Composite by the Wet Chemical Method: Structural, Optical, and Photocatalytic Properties. Ceram. Int. 2013, 39, 9207-9214.

(27) Hummers Jr, W. S.; Offeman, R. E., Preparation of Graphitic Oxide. J. Am. Chem Soc. 1958, 80, 1339-1339. 
(28) Chaaya, A. A.; Bechelany, M.; Balme, S.; Miele, P., ZnO 1D Nanostructures Designed by Combining Atomic Layer Deposition and Electrospinning for Uv Sensor Applications. $J$. Mater. Chem. A 2014, 2, 20650-20658.

(29) Dhakal, T. P.; Hamasha, M. M.; Nandur, A. S.; Vanhart, D.; Vasekar, P.; Lu, S.; Sharma, A.; Westgate, C. R., Moisture-Induced Surface Corrosion in Azo Thin Films Formed by Atomic Layer Deposition. IEEE Trans. Device Mater. Reliab. 2012, 12, 347-356.

(30) Chuangchote, S.; Jitputti, J.; Sagawa, T.; Yoshikawa, S., Photocatalytic Activity for Hydrogen Evolution of Electrospun TiO2 Nanofibers. ACS App. Mater. Interfaces 2009, 1, 1140-1143.

(31) Nalbandian, M. J.; Zhang, M.; Sanchez, J.; Kim, S.; Choa, Y.-H.; Cwiertny, D. M.; Myung, N. V., Synthesis and Optimization of Ag-TiO2 Composite Nanofibers for Photocatalytic Treatment of Impaired Water Sources. J. Hazard. Mater. 2015, 299, 141-148.

(32) Wei, Z.; Li, Y.; Luo, S.; Liu, C.; Meng, D.; Ding, M.; Zeng, G., Hierarchical Heterostructure of Cds Nanoparticles Sensitized Electrospun TiO2 Nanofibers with Enhanced Photocatalytic Activity. Sep. Purif. Technol. 2014, 122, 60-66.

(33) Eid, C.; Assaf, E.; Habchi, R.; Miele, P.; Bechelany, M., Tunable Properties of GoDoped Cofe 2 O 4 Nanofibers Elaborated by Electrospinning. RSC Adv. 2015, 5, 9784997854.

(34) Wang, G.; Wang, B.; Park, J.; Yang, J.; Shen, X.; Yao, J., Synthesis of Enhanced Hydrophilic and Hydrophobic Graphene Oxide Nanosheets by a Solvothermal Method. Carbon 2009, 47, 68-72.

(35) Srinivas, G.; Zhu, Y.; Piner, R.; Skipper, N.; Ellerby, M.; Ruoff, R., Synthesis of Graphene-Like Nanosheets and Their Hydrogen Adsorption Capacity. Carbon 2010, 48, 630635.

(36) Nasr, M.; Chaaya, A. A.; Abboud, N.; Bechelany, M.; Viter, R.; Eid, C.; Khoury, A.; Miele, P., Photoluminescence: A Very Sensitive Tool to Detect the Presence of Anatase in Rutile Phase Electrospun TiO2 Nanofibers. Superlattices Microstruct. 2015, 77, 18-24.

(37) Pastrana-Martínez, L. M.; Morales-Torres, S.; Likodimos, V.; Figueiredo, J. L.; Faria, J. L.; Falaras, P.; Silva, A. M., Advanced Nanostructured Photocatalysts Based on Reduced Graphene Oxide-TiO2 Composites for Degradation of Diphenhydramine Pharmaceutical and Methyl Orange Dye. Appl. Catal., B 2012, 123, 241-256.

(38) Štengl, V.; Bakardjieva, S.; Grygar, T. M.; Bludská, J.; Kormunda, M., Tio2-Graphene Oxide Nanocomposite as Advanced Photocatalytic Materials. Chem. Cent. J 2013, 7, 41.

(39) Luo, D.; Zhang, G.; Liu, J.; Sun, X., Evaluation Criteria for Reduced Graphene Oxide. J. Phys. Chem. C 2011, 115, 11327-11335.

(40) Xue, Y.; Wu, B.; Bao, Q.; Liu, Y., Controllable Synthesis of Doped Graphene and Its Applications. Small 2014, 10, 2975-2991.

(41) Guo, Y.; Sun, X.; Liu, Y.; Wang, W.; Qiu, H.; Gao, J., One Pot Preparation of Reduced Graphene Oxide (RGO) or $\mathrm{Au}$ (Ag) Nanoparticle-Rgo Hybrids Using Chitosan as a Reducing and Stabilizing Agent and Their Use in Methanol Electrooxidation. Carbon 2012, 50, 2513-2523.

(42) Song, Y.; Qu, K.; Zhao, C.; Ren, J.; Qu, X., Graphene Oxide: Intrinsic Peroxidase Catalytic Activity and Its Application to Glucose Detection. Adv. Mater. 2010, 22, 22062210.

(43) Zhai, C.; Zhu, M.; Lu, Y.; Ren, F.; Wang, C.; Du, Y.; Yang, P., Reduced Graphene Oxide Modified Highly Ordered TiO2 Nanotube Arrays Photoelectrode with Enhanced Photoelectrocatalytic Performance under Visible-Light Irradiation. Phys. Chem. Chem. Phys. 2014, 16, 14800-14807. 
(44) Doh, S. J.; Kim, C.; Lee, S. G.; Lee, S. J.; Kim, H., Development of Photocatalytic TiO2 Nanofibers by Electrospinning and Its Application to Degradation of Dye Pollutants. $J$. Hazard. Mater. 2008, 154, 118-127.

(45) Zhou, K.; Zhu, Y.; Yang, X.; Jiang, X.; Li, C., Preparation of Graphene-TiO2 Composites with Enhanced Photocatalytic Activity. New J. Chem. 2011, 35, 353-359.

(46) Zhang, X.-Y.; Li, H.-P.; Cui, X.-L.; Lin, Y., Graphene/TiO2 Nanocomposites: Synthesis, Characterization and Application in Hydrogen Evolution from Water Photocatalytic Splitting. J. Mater. Chem. 2010, 20, 2801-2806.

(47) Ohtani, B., Preparing Articles on Photocatalysis-Beyond the Illusions, Misconceptions, and Speculation. Chem. lett. 2008, 37, 216-229.

(48) Konstantinou, I. K.; Albanis, T. A., TiO2-Assisted Photocatalytic Degradation of Azo Dyes in Aqueous Solution: Kinetic and Mechanistic Investigations: A Review. Appl. Catal., B 2004, 49, 1-14.

(49) Huang, S.-Y.; Ganesan, P.; Park, S.; Popov, B. N., Development of a Titanium Dioxide-Supported Platinum Catalyst with Ultrahigh Stability for Polymer Electrolyte Membrane Fuel Cell Applications. J. Am. Chem. Soc. 2009, 131, 13898-13899. 


\section{FIGURES}
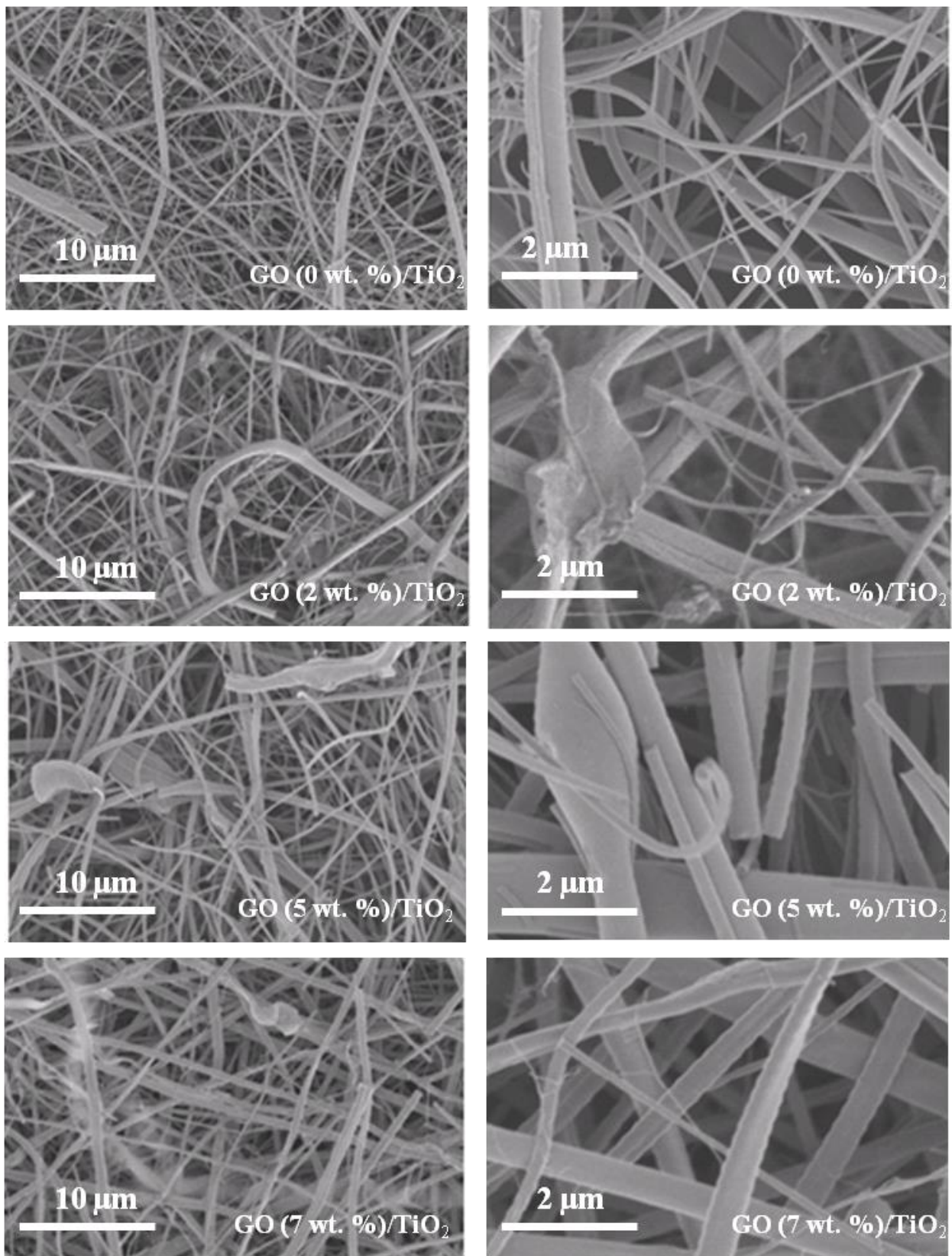

Figure 1. Scanning Electron Microscope images of $\mathrm{TiO}_{2}$ and $\mathrm{GO} / \mathrm{TiO}_{2}$ annealed composite nanofibers under $\mathrm{N}_{2}$ atmosphere for $6 \mathrm{~h}$ at $500^{\circ} \mathrm{C}$. 


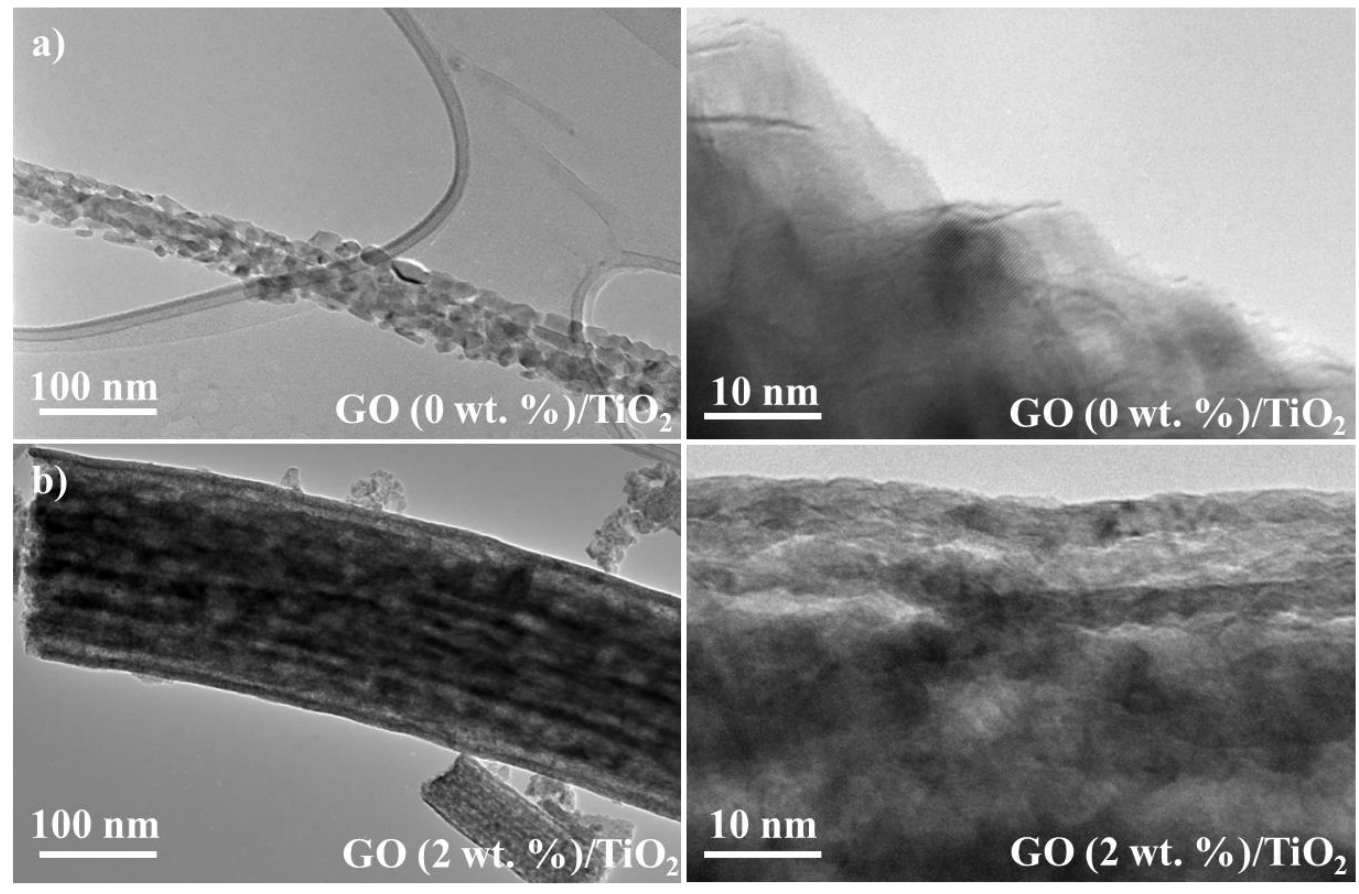

Figure 2. Transmission electron microscopy images of $\mathrm{TiO}_{2} \mathrm{GO}\left(2\right.$ wt. \%) $/ \mathrm{TiO}_{2}$ annealed nanofibers under $\mathrm{N}_{2}$ atmosphere for $6 \mathrm{~h}$ at $500^{\circ} \mathrm{C}$. 


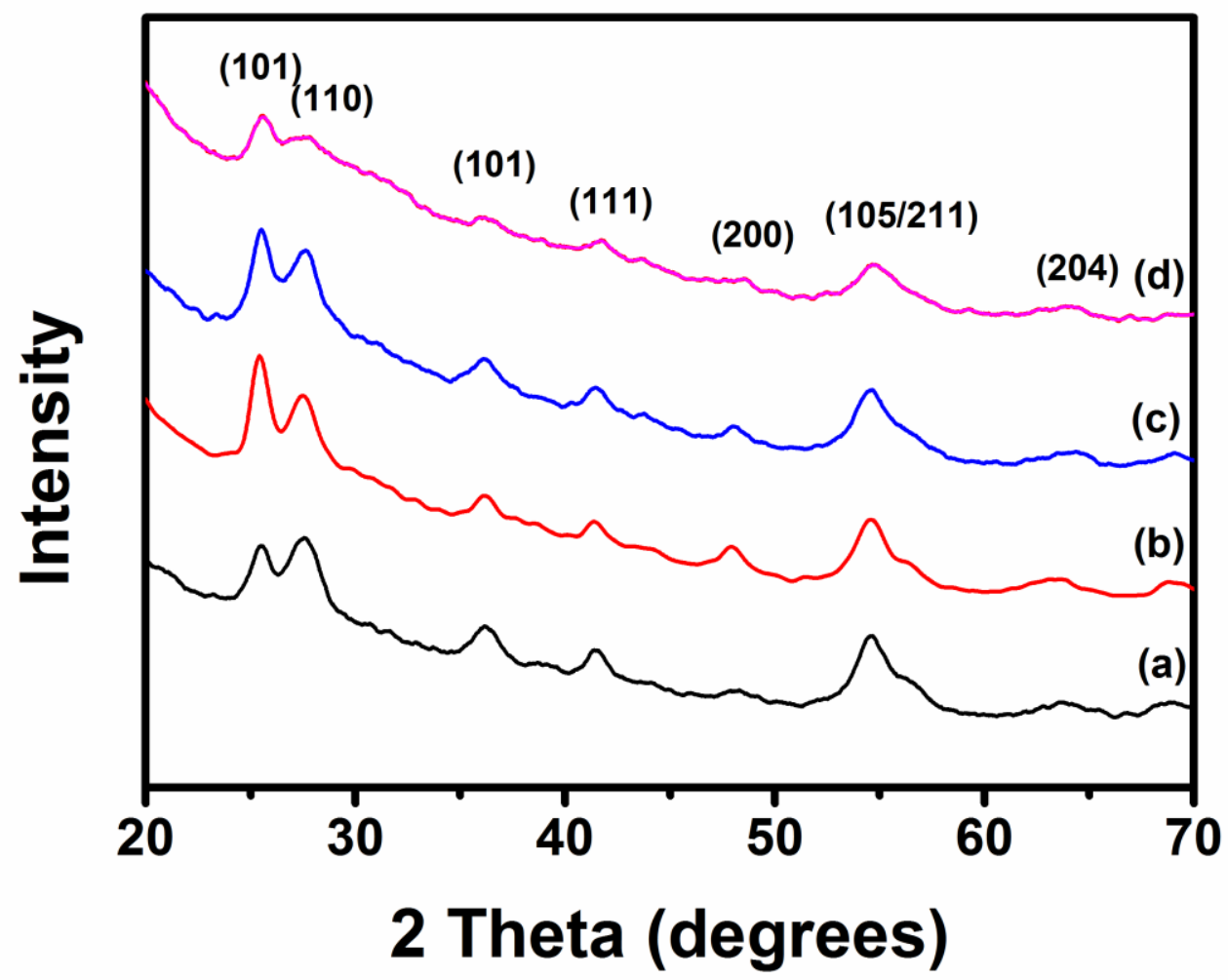

Figure 3. XRD patterns of photocatalysts: (a) $\mathrm{TiO}_{2}$, (b) $\mathrm{GO}\left(2\right.$ wt. \%) $/ \mathrm{TiO}_{2}$, (c) $\mathrm{GO}(5 \mathrm{wt} . \%$ ) $/ \mathrm{TiO}_{2}$, and (d) GO (7wt. \%) $/ \mathrm{TiO}_{2}$ annealed nanofibers under $\mathrm{N}_{2}$ atmosphere for $6 \mathrm{~h}$ at $500^{\circ} \mathrm{C}$. 

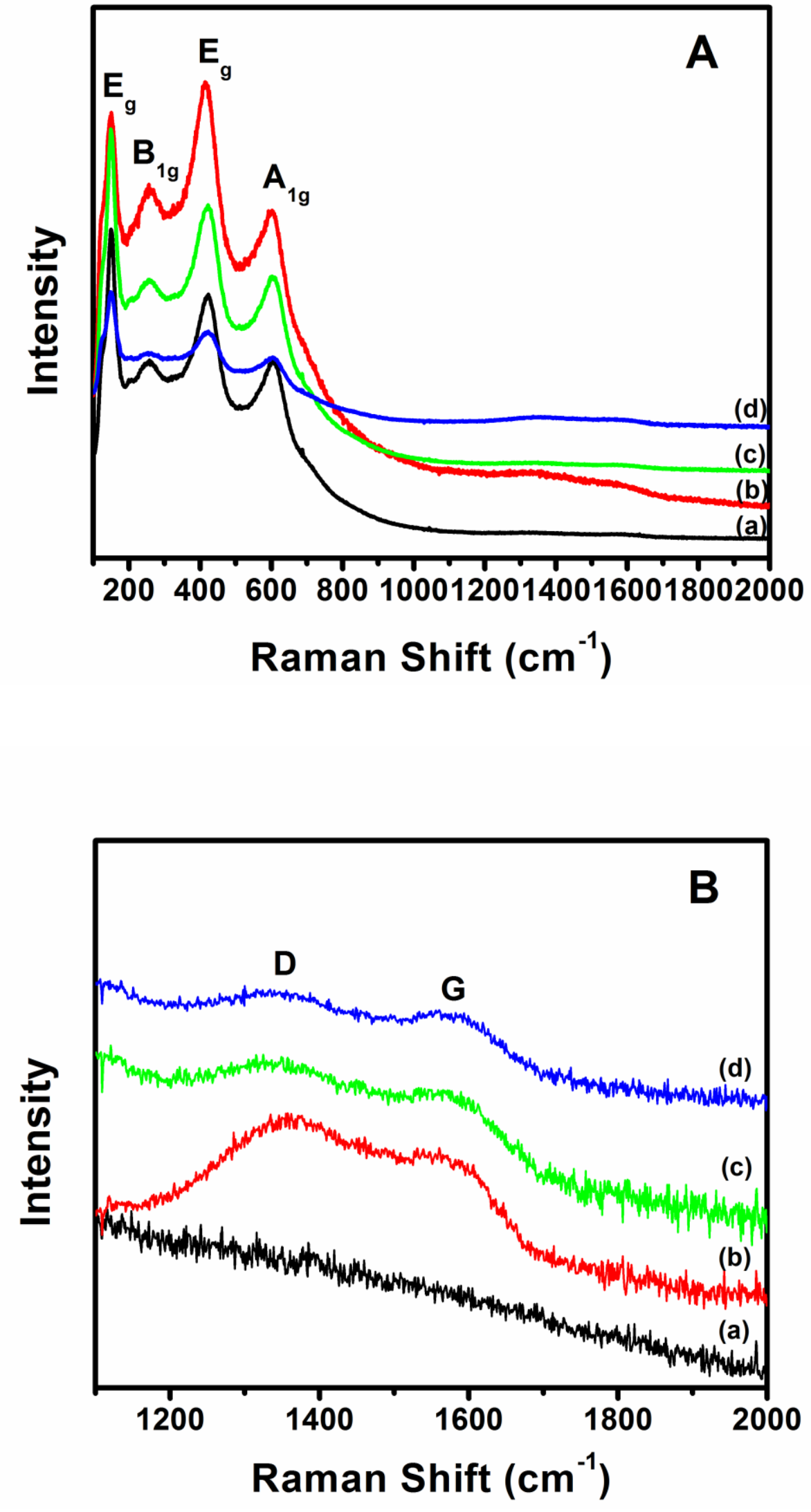
Figure 4. (A-B) Raman Shift of (a) $\mathrm{TiO}_{2}$, (b) GO (2 wt. \%) $/ \mathrm{TiO}_{2}$, (c) $\mathrm{GO}\left(5\right.$ wt. \%) $/ \mathrm{TiO}_{2}$, (d) $\mathrm{GO}(7 \mathrm{wt} . \%) / \mathrm{TiO}_{2}$ annealed nanofibers under $\mathrm{N}_{2}$ atmosphere for $6 \mathrm{~h}$ at $500^{\circ} \mathrm{C}$.

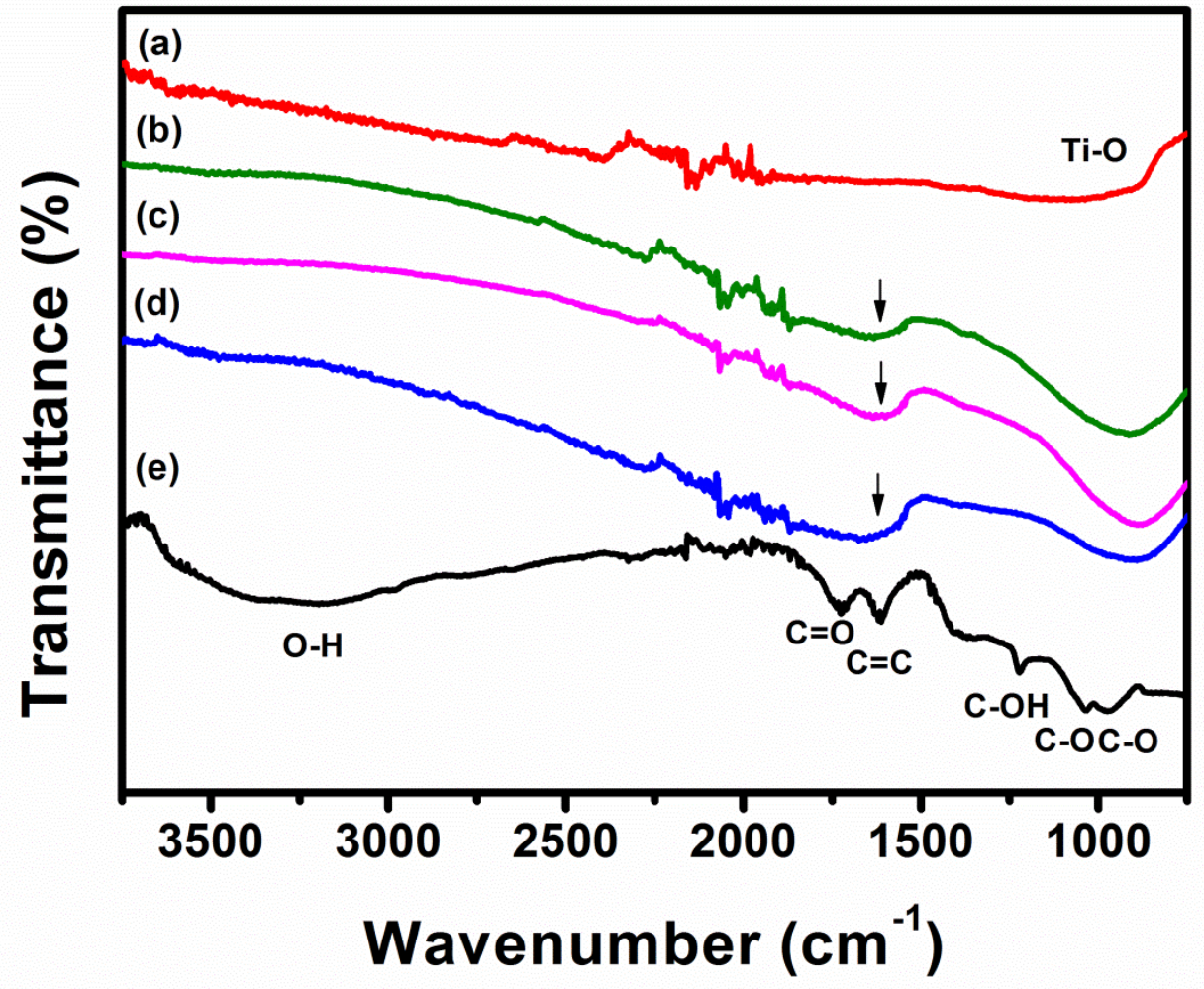

Figure 5. FTIR spectra of (a) $\mathrm{TiO}_{2}$, (b) $\mathrm{GO}\left(2\right.$ wt. \%) $/ \mathrm{TiO}_{2}$, (c) $\mathrm{GO}\left(5\right.$ wt. \%) $/ \mathrm{TiO}_{2}$, (d) $\mathrm{GO}$ (7wt. \%) $/ \mathrm{TiO}_{2} \mathrm{GO}$ annealed nanofibers under $\mathrm{N}_{2}$ atmosphere and (e) GO. 


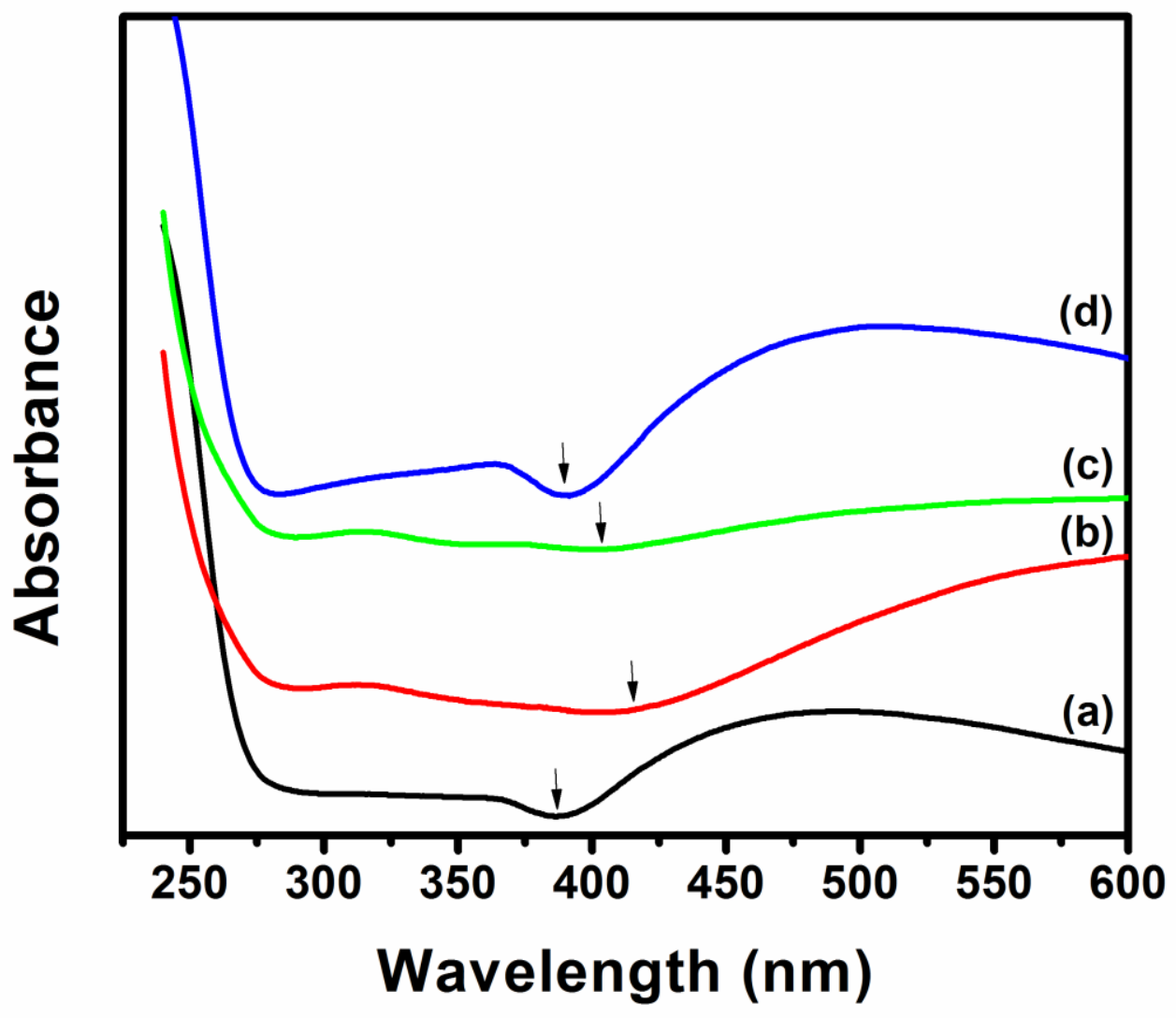

Figure 6. UV-Vis absorption spectra of (a) $\mathrm{TiO}_{2}$, (b) $\mathrm{GO}\left(2\right.$ wt. \%) $/ \mathrm{TiO}_{2}$, (c) $\mathrm{GO}(5 \mathrm{wt} . \%$ ) $/ \mathrm{TiO}_{2},(\mathrm{e}) \mathrm{GO}(7 \mathrm{wt} . \%) / \mathrm{TiO}_{2}$ nanofibers. 

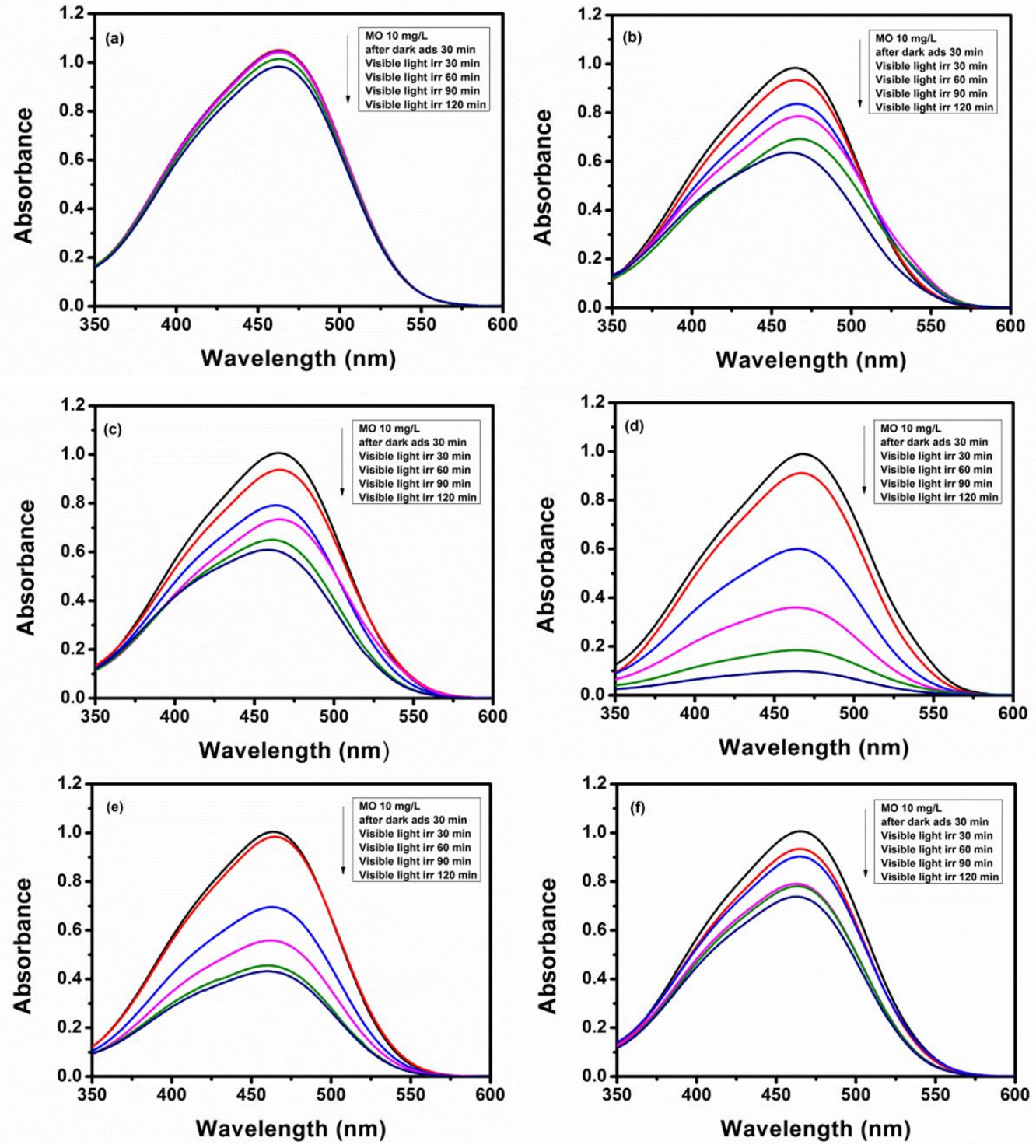

Figure 7. UV-Vis spectra of the photocatalytic degradation of MO under visible light: (a) MO without catalyst, (b) $\mathrm{TiO}_{2}-\mathrm{P} 25$, (c) $\mathrm{TiO}_{2} \mathrm{NFs}$, (d) $\mathrm{GO}\left(2\right.$ wt. \%) $/ \mathrm{TiO}_{2}$, (e) $\mathrm{GO}\left(5 \mathrm{wt} . \%\right.$ ) $/ \mathrm{TiO}_{2}$ and (f) GO (7wt. \%) $/ \mathrm{TiO}_{2}$. 


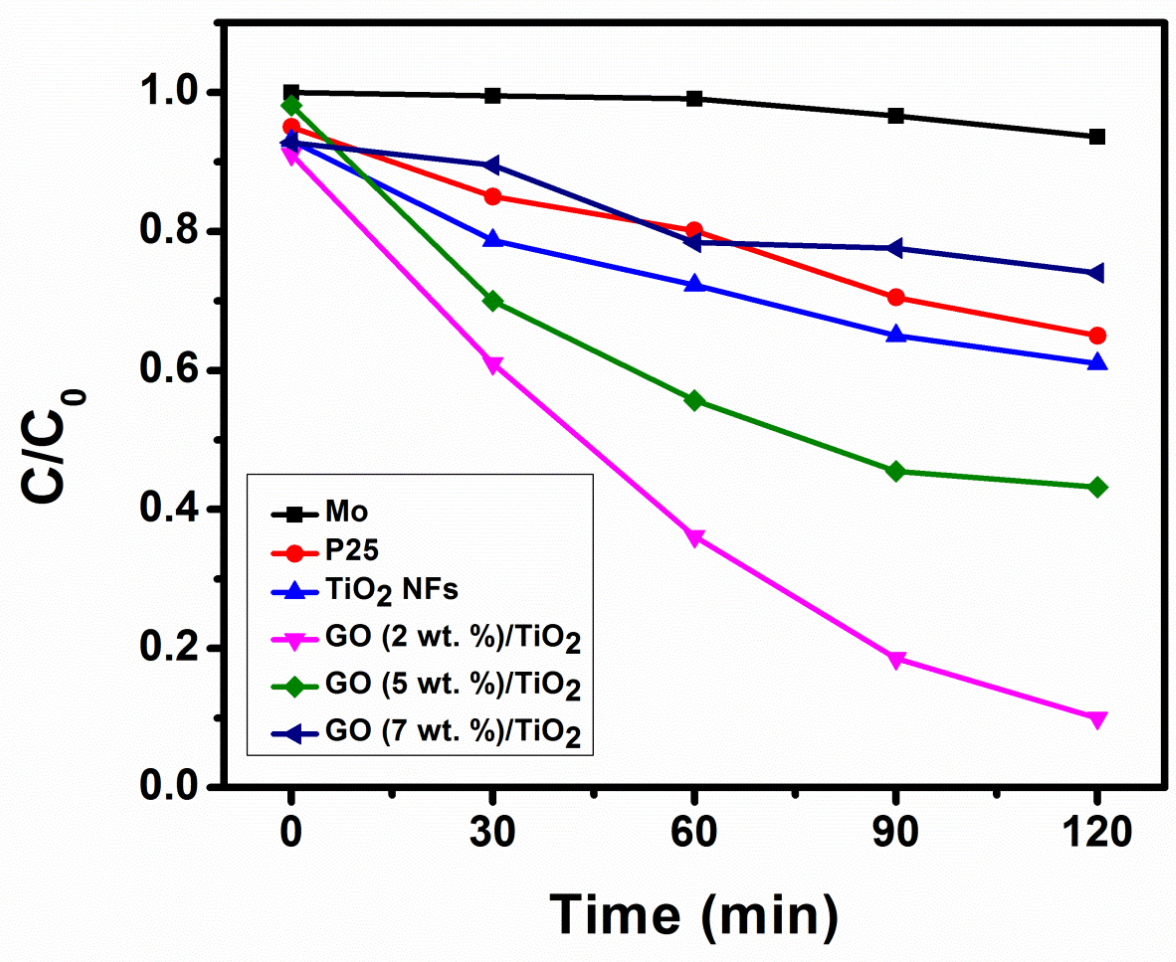

Figure 8. Photodegradation of $\mathrm{MO}$ by $\mathrm{TiO}_{2}-\mathrm{P} 25, \mathrm{TiO}_{2} \mathrm{NFs}$ and $\mathrm{rGO} / \mathrm{TiO}_{2}$ composite nanofibers.

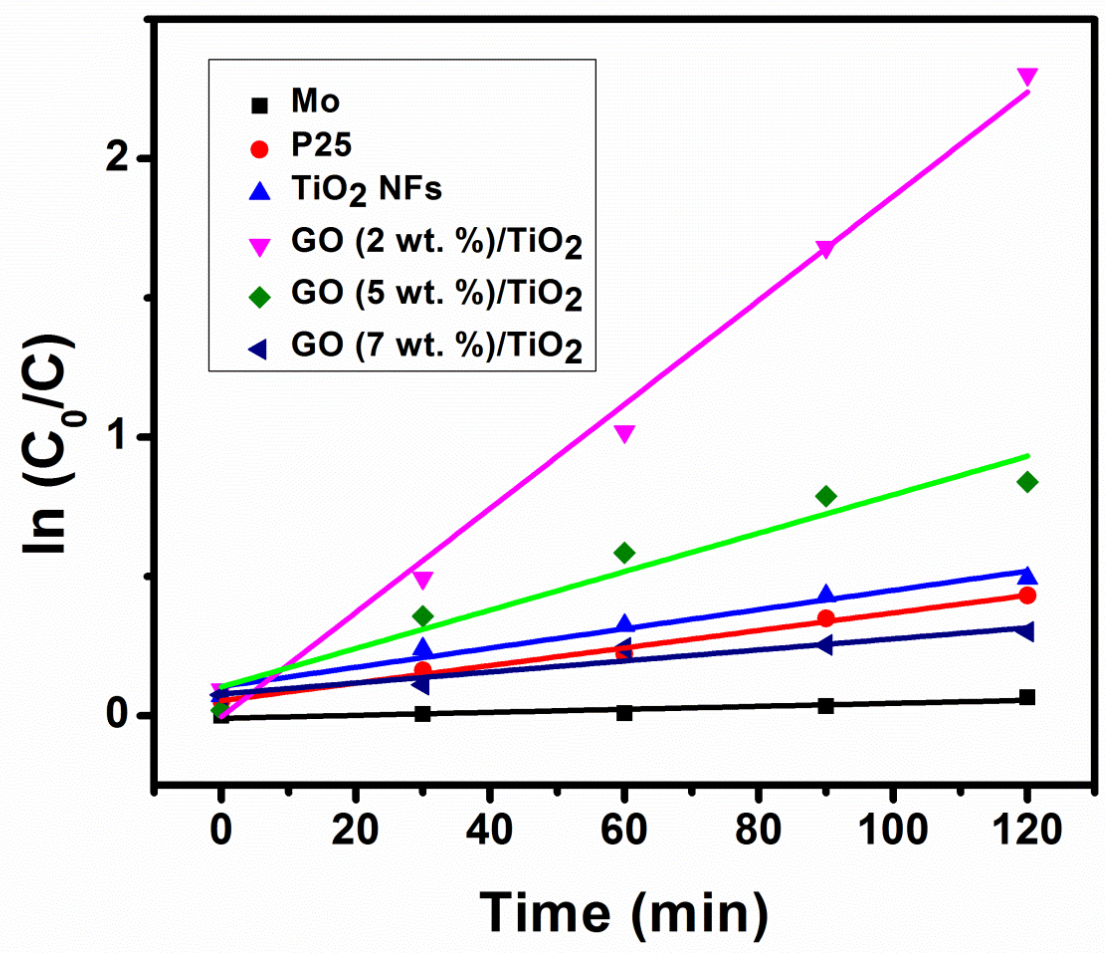


Figure 9. Kinetics of Methyl orange degradation by $\mathrm{TiO}_{2}-\mathrm{P} 25, \mathrm{TiO}_{2} \mathrm{NFs}$ and $\mathrm{rGO} / \mathrm{TiO}_{2}$ composite nanofibers. 


\section{TABLES}

Table 1. EDX data showing the composition of $\mathrm{TiO}_{2}, \mathrm{GO}(2$ wt. $\%) / \mathrm{TiO}_{2}, \mathrm{GO}\left(5\right.$ wt. \%) $/ \mathrm{TiO}_{2}$ and $\mathrm{GO}(7 \mathrm{wt} . \%) / \mathrm{TiO}_{2}$ annealed nanofibers under $\mathrm{N}_{2}$ atmosphere

\section{Atomic percentages}

\begin{tabular}{cccc}
\hline Samples & $\mathrm{Ti}$ & $\mathrm{O}$ & $\mathrm{C}$ \\
$\mathrm{TiO}_{2}$ & 30.49 & 60.76 & 8.75 \\
$\mathrm{GO}(2$ wt. \%) & 30.89 & 58.31 & 10.8 \\
$\mathrm{GO}(5$ wt. \%) & 29.29 & 53.26 & 17.45 \\
GO (7 wt. \%) & 24.98 & 52.07 & 22.95 \\
\hline
\end{tabular}

Table 2. Kinetic parameters for photocatalytic activities of $\mathrm{TiO}_{2}-\mathrm{P} 25, \mathrm{TiO}_{2} \mathrm{NFs}$ and $\mathrm{rGO} / \mathrm{TiO}_{2}$ composite nanofibers

\begin{tabular}{|c|c|c|c|c|c|c|}
\hline & MO & $\mathrm{TiO}_{2}-\mathrm{P} 25$ & $\mathrm{TiO}_{2} \mathrm{NFs}$ & $\begin{array}{c}\text { GO (2 wt. \%) } \\
/ \mathrm{TiO}_{2}\end{array}$ & $\begin{array}{c}\text { GO (5wt. \%) } \\
/ \mathrm{TiO}_{2}\end{array}$ & $\begin{array}{c}\text { GO (7wt. \%) } \\
/ \mathrm{TiO}_{2}\end{array}$ \\
\hline $\mathrm{k}_{\mathrm{a}}\left(\min ^{-1}\right)$ & 0.0005 & 0.0031 & 0.0034 & 0.0186 & 0.0069 & 0.0019 \\
\hline $\mathrm{R}^{2}$ & 0.8146 & 0.9882 & 0.9628 & 0.9885 & 0.9230 & 0.8929 \\
\hline
\end{tabular}


TOC Graphic

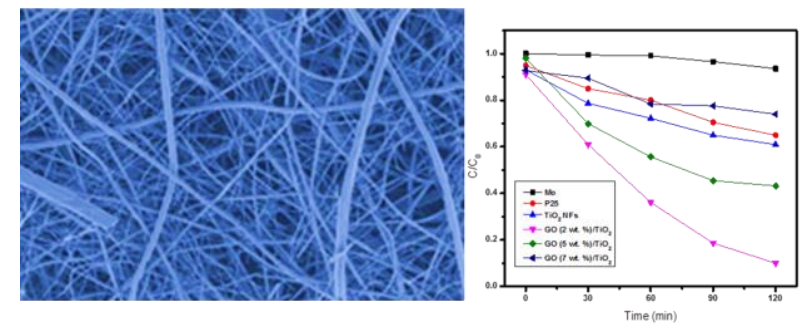

